\title{
BMJ Open Are anxiety levels associated with the decision to participate in a Swedish colorectal cancer screening programme? A nationwide cross-sectional study
}

\author{
Johanna Wangmar, ${ }^{1}$ Ann-Christin von Vogelsang, ${ }^{2,3}$ Rolf Hultcrantz, ${ }^{4}$ \\ Kaisa Fritzell, ${ }^{1,5}$ Yvonne Wengström, ${ }^{1,5}$ Anna Jervaeus ${ }^{1}$
}

To cite: Wangmar J, von Vogelsang A-C, Hultcrantz R, et al. Are anxiety levels associated with the decision to participate in a Swedish colorectal cancer screening programme? A nationwide cross-sectional study. BMJ Open 2018;8:e25109. doi:10.1136/ bmjopen-2018-025109

- Prepublication history for this paper is available online. To view these files, please visit the journal online (http://dx.doi org/10.1136/bmjopen-2018025109).

Received 29 June 2018 Revised 29 0ctober 2018 Accepted 7 November 2018

\section{Check for updates}

(c) Author(s) (or their employer(s)) 2018. Re-use permitted under CC BY-NC. No commercial re-use. See rights and permissions. Published by BMJ.

${ }^{1}$ Department of Neurobiology, Care Sciences and Society, Division of Nursing, Karolinska Institutet, Stockholm, Sweden

${ }^{2}$ Theme Neuro, Karolinska University Hospital, Stockholm, Sweden

${ }^{3}$ Department of Clinical Neuroscience, Karolinska Institutet, Stockholm, Sweden ${ }^{4}$ Department of Medicine, Karolinska Institutet, Stockholm, Sweden

${ }^{5}$ Theme Cancer, Karolinska University Hospital, Stockholm, Sweden

Correspondence to Johanna Wangmar; johanna.wangmar@ki.se

\section{ABSTRACT}

Objectives Colorectal cancer (CRC) screening programmes are commonly challenged by low uptake, limiting their potential to reduce CRC burden. We aimed to investigate anxiety levels related to the decision to participate or not in CRC screening among screening participants and non-participants. Further to explore associations between higher anxiety levels related to the decision and individuals' characteristics.

Design A nationwide cross-sectional study conducted with individuals included in a national randomised controlled CRC screening trial, the Screening of Swedish Colons (SCREESCO).

Participants A total of 1409 individuals, 60-62 years, recruited from SCREESCO during 2015-2016 participated in the study; 1256 had participated in CRC screening (faecal immunochemical test: $n=958$; colonoscopy: $n=298$ ) and 153 had declined screening participation.

Measures Anxiety levels were assessed with the State-Trait Anxiety Inventory (STAI) S-Anxiety Scale. Health literacy (HL) was assessed with the Swedish Functional and Communicative and Critical Health Literacy Scales.

Results Altogether, $79 \%$ of survey participants reported lower anxiety levels regarding their CRC screening decision (STAl S-Anxiety <40). Anxiety levels did not differ between screening participants and nonparticipants (mean STAI S-Anxiety score $=34.1$ vs 33.9 , $p=0.859$ ). The odds of reporting higher anxiety levels increased by female sex $(\mathrm{OR}=1.37$; $\mathrm{Cl} 1.04$ to 1.80 ; $\mathrm{p}=0.025)$ and previous faecal sampling $(\mathrm{OR}=1.53 ; \mathrm{Cl}$ 1.14 to $2.05 ; p=0.004)$, and decreased if living with partner ( $0 \mathrm{R}=0.65 ; \mathrm{Cl} 0.48$ to $0.88 ; \mathrm{p}=0.005$ ), working $(\mathrm{OR}=0.72 ; \mathrm{Cl} 0.53$ to $0.96 ; \mathrm{p}=0.027)$ or having sufficient $\mathrm{HL}$ (functional: $\mathrm{OR}=0.49 ; \mathrm{Cl} 0.33$ to $0.73, \mathrm{p} \leq 0.001$; communicative and critical: $\mathrm{OR}=0.55 ; \mathrm{Cl} 0.38$ to 0.82 ; $\mathrm{p}=0.003$ ).

Conclusions Anxiety levels did not differ between screening participants and non-participants. Higher anxiety scores were associated with certain characteristics. Interventions accounting for these characteristics can be applied to reduce anxiety and facilitate programme acceptance.

Trial registration number NCT02078804; Results.

\section{Strengths and limitations of this study}

- This study was conducted on a large sample of individuals.

- Screening non-participants were included to get their view on participation.

- Data were collected with validated measures making comparisons of results possible.

- Most survey participants belonged to the faecal immunochemical test arm, so conclusions should be drawn with caution.

\section{INTRODUCTION}

As one of the most common cancers among both women and men, with over half of the cases occurring in more developed regions, ${ }^{1}$ colorectal cancer (CRC) remains a European public health concern. In 2014, 153000 people died from CRC in the EU-28, corresponding to approximately $11 \%$ of all cancer-related deaths and $3 \%$ of the total number of deaths from any cause. ${ }^{2}$ Since 2003, the Council of the European Union has recommended organised population-based screening for CRC using a faecal occult blood test in women and men aged 50-74 years. ${ }^{3}$ The aim of CRC screening is to lower the disease burden by finding potential malignancy at an early and treatable stage. ${ }^{45}$ In 2016, 17 Member States of the EU-28 had implemented population-based CRC screening programmes on either a national or regional level. Four member states were piloting a screening programme, two were in a planning phase and five had a non-population based programme or no CRC screening programme at all. ${ }^{6}$

Two critical aspects in the success of any screening programme is the uptake in the targeted population and the acceptance of the programme among those invited. ${ }^{4}$ However, participation rates in CRC screening tend 
to be relatively low and are lower compared with other cancer screening programmes in the EU such as cervical and breast cancer screening. ${ }^{3}$ To be on a desirable level, The European Guidelines for Quality Assurance in CRC screening suggest participation rates of at least $65 \%{ }^{4}$ Though according to a recent international comparison on CRC screening uptake, none of the included European countries reported numbers meeting the target rate set by the European Commission. ${ }^{7}$ Sweden is currently in the planning stage for a national CRC screening programme, but the ongoing regional programme for Stockholm/Gotland County has had an overall participation rate among first invitees of $53 \%{ }^{7}$

In Sweden, some suggested barriers to CRC screening participation have previously been described. ${ }^{89}$ Results from a register-based study showed that being male, single, and having a low income were examples of characteristics associated with non-participation. ${ }^{8}$ Further, having a fatalistic approach towards illness and health was a barrier found in a qualitative study among both CRC screening participants and non-participants. ${ }^{9}$ However, to the best of our knowledge, research on individuals' anxiety level and CRC screening decision is novel.

The impact of anxiety on screening participation seem to vary across screening programmes and cancer types. ${ }^{10-12}$ However, for CRC screening, the screening procedure itself is more complex than in other cancer screening programmes. ${ }^{4}$ This is related to the various screening tests that can be used, whereof colonoscopy and sigmoidoscopy are invasive with known risks for complications and faecal tests fully rely on the individual's own performance, adding further potential sources of anxiety for the invitees. ${ }^{4}$ For example, anxiety and fear about bowel preparation ${ }^{13}$ and worries about discomfort and scoping risks ${ }^{14}$ have been reported to hinder participation in CRC screening programmes with flexible sigmoidoscopy. In addition, cancer fear has been identified as one key reason for non-participation in CRC screening using faecal occult blood and partly due to anticipated anxiety when waiting for test results. ${ }^{15}$ Moreover, widening the perspective from screening participation, a recently published systematic review on CRC screening-related morbidity and mortality, concluded that being invited to CRC screening can cause significant psychological distress, such as anxiety, and that future studies aiming at exploring factors that potentially affect this outcome, such as gender and personality characteristics, are needed. ${ }^{16}$

\section{AIM}

The aim of the present study was to investigate anxiety levels related to the decision to participate or not in a CRC screening programme among both screening participants and non-participants. Further, we aimed to explore associations between higher levels of anxiety related to the decision and individuals' sociodemographic and personal characteristics.
METHOD

\section{Design}

This was a cross-sectional study conducted on individuals included in an ongoing national randomised controlled CRC screening study, the Screening of Swedish Colons (SCREESCO) programme.

\section{Sample}

Survey participants were recruited from the SCREESCO programme between October 2015 and June 2016. A total of 2748 individuals were invited to participate in an online survey-1499 of whom had been randomised to and screened with faecal immunochemical test (FIT), 500 of whom had been randomised to and screened with colonoscopy, and 749 of whom had declined screening participation regardless of randomised screening modality (FIT or colonoscopy). The invited individuals were 60-62 years of age and together represented 18 of Sweden's 21 counties. For more detailed information, please see Wangmar et al. ${ }^{17}$ Of all invitees, 1498 (54.5\%) consented to participate in the survey-1421 responded to the survey online and 77 responded by telephone with help from one of the researchers. For the purpose of this study, individuals with complete anxiety scales were further selected, resulting in 1409 survey participants in the analysis (excluded $n=89$; $5.9 \%)$. For a flow diagram of survey participants and data collection, see figure 1 .

\section{Measures}

Data on sociodemographic and personal characteristics were self-reported through single questions and concerned sex, living situation, occupation, education, previous faecal sampling and previous colonoscopy.

Levels of anxiety were measured with the Swedish version of the State-Trait Anxiety Inventory (STAI) S-Anxiety Scale. The STAI S-Anxiety Scale measures state anxiety (ie, anxiety at a certain point of time or in a specific situation) and consists of 20 items evaluating the presence and severity of different anxiety symptoms such as apprehension, worry, nervousness and tension. All items are self-rated on a 4-point scale of $1=$ not at all, 2=somewhat, $3=$ moderately and $4=$ very much, and they are added to obtain a total score for each respondent. Total scores range from 20 to 80 , with higher scores indicating higher levels of anxiety. ${ }^{18}$ The scale has been tested and validated for the Swedish context. ${ }^{19}$ For individuals aged 46-65 years, the Swedish norm values are 30.8 for men and 36.3 for women. ${ }^{19}$ To detect individuals with clinically significant symptoms of anxiety, a cut-off value of 40 has previously been used in a Swedish study ${ }^{20}$ and was therefore applied in the present study.

Levels of health literacy (HL) were measured with the Swedish Functional Health Literacy (FHL) Scale and the Swedish Communicative and Critical Health Literacy (C\&C HL) Scale, previously described in Wangmar et $a l .{ }^{17}$ Shortly, the scales consist of five items each assessing different aspects of HL; from basic reading skills ${ }^{21}$ to more advanced cognitive and social abilities. ${ }^{22}$ All items 

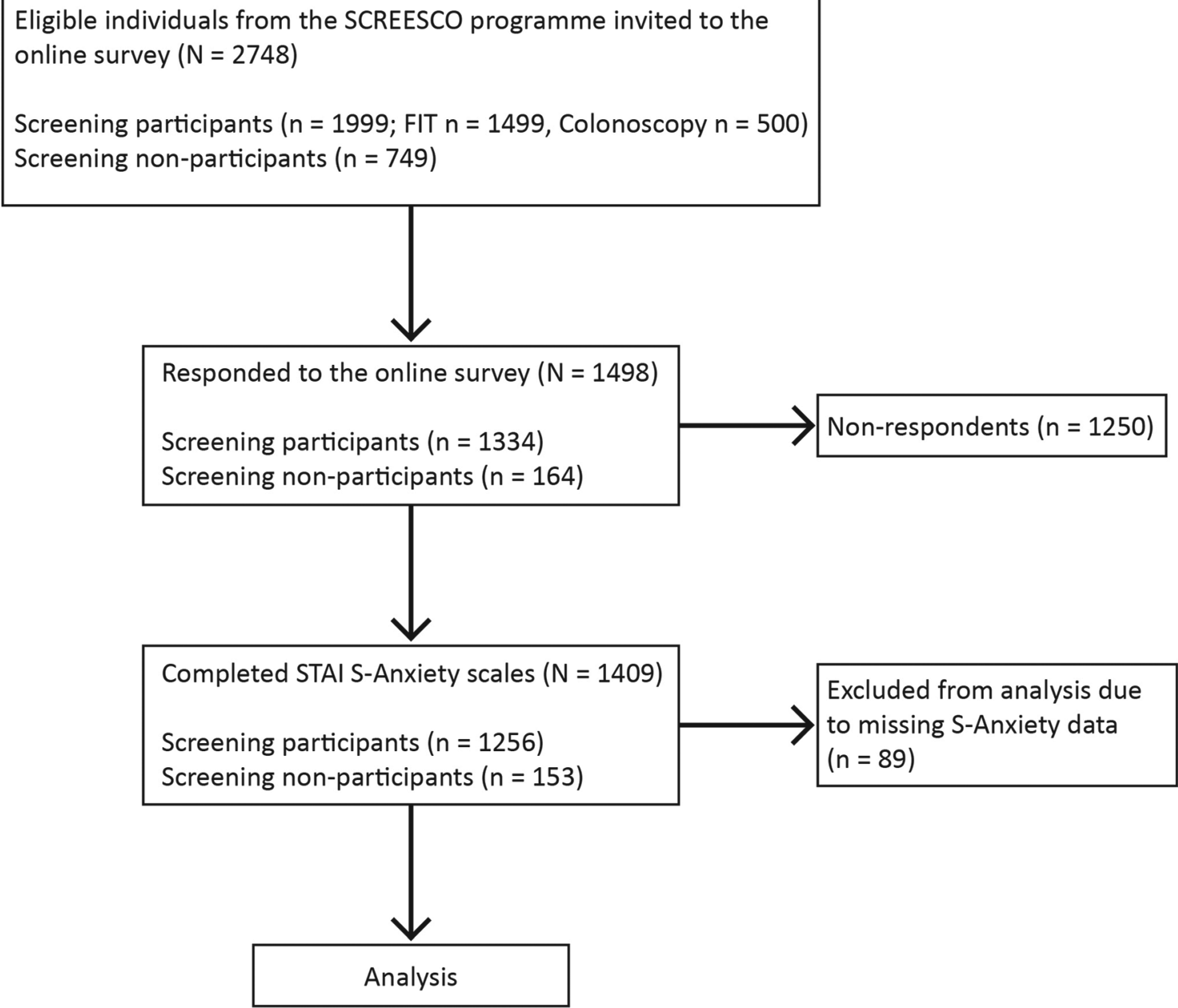

Figure 1 Flow diagram of survey participants and data collection. FIT, faecal immunochemical test; SCREESCO, Screening of Swedish Colons; STAI, State-Trait Anxiety Inventory.

are self-rated on a 5-point Scale ranging from 1 never to 5 always, negatively directed, for the Swedish FHL Scale, ${ }^{21}$ and from $1=$ strongly disagree to $5=$ strongly agree, positively directed, for the Swedish C \& C HL Scale. ${ }^{22}$ To calculate overall levels of HL, each response alternative is given a numerical value of 1,100 or 1000 that are further summarised. When using the scales in a dichotomous form, as in this study, sums above 1000 is interpreted as inadequate HL and sums below 1000 is interpreted as not inadequate HL. ${ }^{21}{ }^{22}$ Both scales are validated for the Swedish context. ${ }^{21} 22$

\section{Procedure}

The procedure has been described in more detail elsewhere. ${ }^{17}$ Shortly, an invitation letter with study information and login details to an online survey was sent to the eligible individuals by mail. When responding to the S-Anxiety Scale, survey participants were encouraged to answer "how you feel right now, in relation to your decision to participate or not in the CRC screening programme'. The time point for completion of the survey was after all screening participants had completed their initial screening test (FIT or colonoscopy depending on randomised screening modality). Screening non-participants completed the survey after declining screening participation.

\section{Data analysis}

First, a comparison regarding sociodemographic characteristics of screening participants and screening non-participants was done using $\mathrm{X}^{2}$ tests. Additionally, Cronbach's $\alpha$ was calculated to test the internal consistency of the STAI S-Anxiety Scale in this population. The S-Anxiety data were normally distributed and an independent samples t-test was used to investigate possible differences in levels of anxiety between those participating and those declining to participate in the SCREESCO programme. Second, individuals were divided into two groups by the chosen cut-off value of 40 on the S-Anxiety Scale, and associations regarding anxiety levels and sociodemographic and personal characteristics were explored using logistic regression with STAI S-Anxiety $\geq 40$ coded as 1 for the dependent variable. A total of nine independent dichotomous variables were entered in the logistic regression model: screening decision, sex, living situation, occupation, education, functional HL, communicative and 
Table 1 Sociodemographic characteristics of survey participants $(n=1409)^{*}$

Screening participants

$n=1256 n(\%)$

Screening non-participants, $\mathrm{n}=153 n(\%)$

P value $\dagger$

\begin{tabular}{|c|c|c|c|}
\hline \multicolumn{4}{|c|}{ Colorectal cancer (CRC) screening allocation group } \\
\hline Faecal immunochemical test & $958(76.3)$ & & \\
\hline Colonoscopy & $298(23.7)$ & & \\
\hline \multicolumn{4}{|l|}{ Sex } \\
\hline Female & $630(50.2)$ & $95(62.1)$ & \multirow[t]{2}{*}{0.007} \\
\hline Male & $626(49.8)$ & $58(37.9)$ & \\
\hline \multicolumn{4}{|l|}{ Living situation $(n=1403)^{\star}$} \\
\hline Living with partner & $990(79.2)$ & $114(74.5)$ & \multirow[t]{2}{*}{0.218} \\
\hline Living alone & $260(20.8)$ & $39(25.5)$ & \\
\hline \multicolumn{4}{|l|}{ Occupation } \\
\hline Working & $946(75.3)$ & $112(73.2)$ & \multirow[t]{2}{*}{0.637} \\
\hline Not working $\ddagger$ & $310(24.7)$ & $41(26.8)$ & \\
\hline \multicolumn{4}{|l|}{ Level of education $(n=1403)^{\star}$} \\
\hline Compulsory school or high school & 779 (62.2) & $88(58.3)$ & \multirow[t]{2}{*}{0.394} \\
\hline Vocational high school or university & $473(37.8)$ & $63(41.7)$ & \\
\hline
\end{tabular}

${ }^{*}$ Different $\mathrm{n}$ due to missing data.

$\dagger$ Tested for differences in proportions by $X^{2}$-test. Significance level set at $p \leq 0.05$. Significant results printed in bold.

fFor example retired, on disability living allowance, or on sick leave.

critical HL, previous faecal sampling and previous colonoscopy. Levels of HL were calculated according to the manuals ${ }^{2122}$ as presented in Wangmar et $\mathrm{al}^{17}$ meaning that individuals scoring $4=$ often or $5=$ always for at least one item in the Swedish FHL Scale and 1=strongly disagree or 2=disagree for at least one item in the Swedish C \& C HL Scale, were classified as having inadequate HL. All statistical analyses were performed in the Statistical Package for the Social Sciences (SPSS V.25), and $p$ values of $\leq 0.05$ were considered statistically significant.

\section{Participant involvement}

The research questions were developed using the experiences of individuals who had been invited to participate in the SCREESCO programme and who had participated in focus group discussions and interviews. Results from the study will be summarised and provided in a popular scientific format using the study website.

\section{RESULTS}

Sociodemographic characteristics of the survey participants with complete STAI S-Anxiety Scales are shown in table 1 . There were no significant differences between screening participants and non-participants, except for sex, with a higher proportion of women in the screening non-participant group $(\mathrm{p}=0.007)$.

The internal consistency of the STAI S-Anxiety Scale in this sample was $\alpha=0.945$. In relation to the decision to participate or not in the CRC screening programme, the results from the S-Anxiety Scale showed no significant differences in levels of anxiety among screening participants $(\mathrm{n}=1256)$ and screening non-participants $(\mathrm{n}=153) \quad$ (mean STAI S-Anxiety score $=34.1$ vs 33.9, $\mathrm{p}=0.859)$.

A total of 21\% ( $n=294)$ of the survey participants scored above the cut-off value for clinically significant anxiety related to their screening decision (STAI-S Anxiety $\geq 40$ ). Results from the logistic regression analysis revealed that the odds of reporting higher levels of anxiety significantly increased by female sex (OR=1.37; CI 1.04 to 1.80 ; $\mathrm{p}=0.025)$ and previous experience of faecal sampling $(\mathrm{OR}=1.53$; CI 1.14 to $2.05 ; \mathrm{p}=0.004)$. Conversely, the odds significantly decreased if one was living with partner $(\mathrm{OR}=0.65$; CI 0.48 to $0.88 ; \mathrm{p}=0.005)$, working $(\mathrm{OR}=0.72$; CI 0.53 to $0.96 ; \mathrm{P}=0.027)$, having sufficient functional HL $(\mathrm{OR}=0.49$; CI 0.33 to $0.73, \mathrm{p} \leq 0.001)$ or sufficient communicative and critical HL $(\mathrm{OR}=0.55$; CI 0.38 to $0.82 ; \mathrm{p}=0.003)$. Screening decision, educational level and previous experience of colonoscopy were non-significant variables in the model. The analysis was conducted on 1377 individuals. The full model was statistically significant $\left(\chi^{2}=67.58, \mathrm{p} \leq 0.001\right)$ and suggested to account for 4.8 (Cox \& Snell $\mathrm{R}^{2}$ ) to $7.5 \%$ (Nagelkerke $\mathrm{R}^{2}$ ) of the variance in anxiety levels in this sample. For more detailed information, see table 2.

\section{DISCUSSION}

Our study showed no significant differences regarding levels of anxiety among those who participated in the CRC screening programme in comparison to those who did not. Both groups displayed a mean STAI S-Anxiety score 
Table 2 Associations between higher levels of anxiety related to CRC screening decision and individuals' sociodemographic and personal characteristics $(n=1377)$

Odds ratios of reporting STAI S-Anxiety $\geq 40$

OR $\quad 95 \% \mathrm{Cl}$ for OR P value $^{*}$

CRC screening decision

Non-participation 1 (ref.)

$\begin{array}{llll}\text { Participation } & 0.96 & 0.63-1.49 & 0.865\end{array}$

Sex

$\begin{array}{llll}\text { Male } & 1 \text { (ref.) } & & \mathbf{0 . 0 2 5}\end{array}$

Living situation

Living alone 1 (ref.)

$\begin{array}{llll}\text { Living with partner } & 0.65 & 0.48-0.88 & 0.005\end{array}$

Occupation

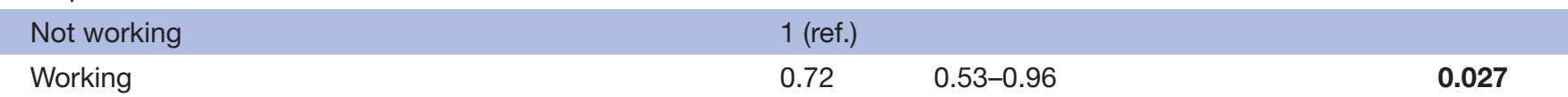

Level of education

Compulsory school or high school 1 (ref.)

Vocational high school or university $\quad 0.86$

$0.64-1.14$

Level of functional health literacy

Inadequate 1 (ref.)

$\begin{array}{llll}\text { Not inadequate } & 0.49 & 0.33-0.73 & <0.001\end{array}$

Level of communicative and

critical health literacy

Inadequate

1 (ref.)

Not inadequate $\quad 0.55$

$0.38-0.82$

0.003

Previous faecal sampling

\begin{tabular}{llll} 
No & 1 (ref.) & & $\mathbf{0 . 0 0 4}$ \\
Yes & 1.53 & $1.14-2.05$ & \\
Previous colonoscopy & & & 0.125 \\
No & 1 (ref.) & & $0.94-1.67$ \\
\hline
\end{tabular}

Significant results printed in bold.

*Significance level set at $p \leq 0.05$.

ref.=reference category.

close to the Swedish norm data for individuals of similar age, and altogether 79\% ( $\mathrm{n}=1115)$ scored below the STAI S-Anxiety cut-off of 40. In this sample, the findings show that most people experience low levels of anxiety in relation to their CRC screening decision irrespective of the decision made.

While most of survey participants reported lower anxiety scores, 21\% experienced clinically significant anxiety related to their screening decision, and having higher anxiety levels was significantly associated with certain sociodemographic and personal characteristics. There is a possibility that some of these findings reflect general patterns of anxiety within the studied sample, though to the best of our knowledge no up-to-date comparing data from the general population are available.
Higher levels of anxiety were significantly associated with sex, with women more likely to report a S-Anxiety value $\geq 40$. These findings are in line with previous research on CRC worry and CRC screening-related anxiety, reporting women to be more worried about $\mathrm{CRC}^{23}$ and more anxious about having a CRC screening test. ${ }^{23}{ }^{24}$ However, it should be noted that women generally yield higher scores than men on explicit anxiety measures. ${ }^{25}$ Also, the Swedish population norms for the STAI S-Anxiety Scale are higher for women in this age range.$^{19}$ Likewise to female sex, individuals with previous experience of faecal sampling were more likely to experience higher anxiety levels related to their screening decision. Even if collecting a faecal test sometimes is associated with unpleasantness, ${ }^{26}$ embarrassment ${ }^{26} 27$ 
and concerns about hygiene and contamination, ${ }^{27}$ it is in general well accepted. ${ }^{28}{ }^{29}$ That said, there might be another explanation to this association than the experience of faecal sampling itself. For example, it could be due to some confounding variable that our model did not control for, like comorbidities or a past medical history of gastrointestinal problems, why this association needs further exploration.

We also found a significant association indicating that people living alone were more likely to experience higher levels of anxiety related to their screening decision. Partly, this could be explained by the absence of someone to discuss the decision with, since significant others have been identified as an important discussion partner for individuals attending CRC screening. ${ }^{9}$ Moreover, another explanation might be anxiety over how to face a potential cancer diagnosis on one's own. In a broader sense, lack of social support has similarly been reported to be associated with increased cancer worry. ${ }^{30}$ Although social support is not equal to living situation, these variables might have some meanings in common for some people, potentially explaining the heterogeneity in these results. Further, the lower odds for reporting higher anxiety scores among working individuals, indicated that those not working were more likely to have a S-Anxiety value $\geq 40$. Non-working individuals partly included those on disability living allowance and on sick leave, which might point towards a more vulnerable group with already existing health issues and therefore perhaps who are more prone to experience disease-related anxiety. Such associations have been found in other studies, ${ }^{30} 31$ both for individuals with poorer self-perceived health, an increasing number of health problems, and some functional limitations ${ }^{30}$ and for individuals who are chronically ill. ${ }^{31}$ For those, cancer concerns were derived from a fear of additional life burden and threats to survival, and some were even unwilling to participate in CRC screening because a potential cancer diagnosis was considered too overwhelming when already struggling with several other serious health problems. ${ }^{31}$

Lastly, we found results suggesting that individuals with inadequate HL were more likely to experience higher anxiety levels. It is well known that lower levels of HL are linked to poorer health-related outcomes in several areas, ${ }^{32}$ however, knowledge regarding the relationship between anxiety and HL in a general population facing cancer screening is novel. Literacy skills in general and their potential impact on CRC screening attitudes has been studied among male veterans, showing that men with limited literacy skills were twice as likely to have concerns of the potential messiness and inconvenience of a faecal test. ${ }^{33}$ Yet with regard to screening with flexible sigmoidoscopy, no such differences were found. ${ }^{33} \mathrm{~A}$ relationship concerning higher levels of anxiety and low HL has also been reported for people with coronary heart disease, with the suggested explanation that this might partly be due to the increased struggle in understanding information within this group. ${ }^{34}$ This might also be the case in our sample, though having anxiety per se might also hinder individuals in processing and assimilating the screening information they are provided with.

This study has some limitations. For one, being a part of a larger study influencing sampling, around half of the invited individuals belonged to the FIT arms (positive and negative test results). Together with the challenges in recruiting non-participants to research, this resulted in different-sized groups with predominantly FIT participants in our study population, potentially affecting the ability to draw conclusions. Nevertheless, the large sample size was an advantage per se and especially the inclusion of screening non-participants. There was a significantly higher number of women in the screening non-participant group. Moreover, due to timing of the survey, there is a possibility that answers of screening participants might have been influenced by their initial screening result. We collected our data with the STAI S-Anxiety Scale, which has been frequently used in other studies assessing screening-related anxiety ${ }^{35}$ thus facilitating comparisons of findings. Further, we showed good internal consistency of the scale by calculating a Cronbach's $\alpha=0.9450 .{ }^{36}$ Though with regard to the logistic regression model used for our secondary aim, the independent variables chosen in this study only explained a low amount of the variation in anxiety levels $(4.8 \%-7.5 \%)$, indicating that there are other factors of importance for this outcome (eg deprivation level, comorbidities or perceived CRC risk). This, together with the fact that no analysis between survey respondents versus non-respondents could be done due to lack of data to compare, somewhat limit the generalisability of results.

Irrespective of the limitations, our study provides valuable insights regarding anxiety levels and CRC screening decisions in Sweden and above all it presents certain characteristics associated with individuals experiencing higher levels of anxiety related to their screening decision. This new knowledge can serve as a basis for forthcoming studies on anxiety in CRC screening. Moreover, it can serve supportive for numerous actions aiming to lower the psychological burden and thus facilitate the acceptance of CRC screening programmes. In Sweden, the current invitation to the SCREESCO programme, including an information letter and a short brochure with coloured pictures, is distributed by postal mail. Based on our previous results, ${ }^{917}$ we have suggested more dynamic approaches for communicating CRC screening information to better account for different needs and preferences $^{9}$ and to make the message more health literate. ${ }^{17}$ Because providing information can reduce state anxiety, ${ }^{37}$ these suggestions seem to be further supported by our most recent findings. This especially concerns those approaches enabling interaction, such as telephone support from healthcare personnel and chat functions, and those addressing people with low HL, such as narrative films and spoken texts, due to the significant associations between anxiety levels, living situation and levels of HL. Information leaflets combined with video 
information prior to examination have also been found to reduce anxiety levels in women undergoing colposcopy ${ }^{38}$ further arguing for their usefulness in decreasing screening-related anxiety. Moreover, for individuals facing planned medical interventions, information containing facts on potential discomfort and how to avoid it has been reported to be important for decreasing anxiety. ${ }^{37}$ Likewise, it is important to include a description of how the intervention is performed and what signs indicate that it is proceeding normally. ${ }^{37}$ When applicable, knowledge that the intervention has been done frequently and is undertaken by a clinician with expertise in the field can reduce worries. ${ }^{37}$ The above mentioned factors might also apply to individuals offered CRC screening. However, because there are individual differences in the amount of information needed for individuals to feel reassured, ${ }^{37}$ non-detailed information should be provided as well.

Based on our results, further research on anxiety levels and CRC screening decisions is needed, partially to confirm our findings but also to focus on deprivation level, ethnicity, comorbidities, medical history, CRC knowledge and perceived CRC risk, aspects not covered within this study. In addition, we suggest future studies to continue investigating the mechanisms that potentially influence individuals' CRC screening decision in order to increase the understanding of non-participation, including both individual, organisational and societal factors.

\section{CONCLUSION}

In a Swedish population sample, anxiety levels regarding the decision to participate or not in CRC screening did not differ between screening participants and non-participants. Higher anxiety scores related to the decision were significantly associated with sex, living situation, occupation, levels of HL and previous experience of faecal sampling. Knowing this, several tailored interventions accounting for these characteristics and aiming at reducing anxiety can be supported, further facilitating the acceptance of CRC screening programmes and minimising unnecessary psychological harm.

Acknowledgements The authors would like to acknowledge all of the survey participants.

Contributors JW: Statistical analysis, interpretation of results and manuscript writing; A-CvV: Statistical analysis, interpretation of results and manuscript writing; RH: Study planning and senior adviser; KF: Study planning; data collection, interpretation of results and manuscript writing; YW: Study planning, data collection, interpretation of results and manuscript writing; AJ: Study planning, data collection, interpretation of results and manuscript writing. All authors have read and approved the final manuscript.

Funding This study was supported by grants from the Swedish Association of Local Authorities and Regions and from the Doctoral School in Health Care Sciences at Karolinska Institutet.

Competing interests None declared.

Patient consent for publication Obtained.

Ethics approval Ethics Review Board at Karolinska Institutet, Stockholm, Sweden (No. 2012/2058-31/3).

Provenance and peer review Not commissioned; externally peer reviewed.
Data sharing statement Requests for access to data should be addressed to the corresponding author.

Open access This is an open access article distributed in accordance with the Creative Commons Attribution Non Commercial (CC BY-NC 4.0) license, which permits others to distribute, remix, adapt, build upon this work non-commercially, and license their derivative works on different terms, provided the original work is properly cited, appropriate credit is given, any changes made indicated, and the use is non-commercial. See: http://creativecommons.org/licenses/by-nc/4.0/.

\section{REFERENCES}

1. Ferlay J, Soerjomataram I, Dikshit R, et al. Cancer incidence and mortality worldwide: sources, methods and major patterns in GLOBOCAN 2012. Int J Cancer 2015;136:E359-86.

2. Eurostat. Cancer statistics - specific cancers. 2017 25. 2017 http:// ec.europa.eu/eurostat/statistics-explained/index.php?title=Cancer_ statistics_-_specific_cancers\#Colorectal_cancer (Accessed 8 May 2018).

3. Ponti A, Anttila A, Ronco G, et al. Cancer screening in the European Union (2017). Report on the implementation of the Council Recommendation on cancer screening (second report). Brussels: European Commission, 2017.

4. In: Segnan N, Patrick J, von Karsa L, eds. European guidelines for quality assurance in colorectal cancer screening and diagnosis. first edition. 1st ed.. Luxembourg: Publications Office of the European Union, 2010.

5. Zauber AG. The impact of screening on colorectal cancer mortality and incidence: has it really made a difference? Dig Dis Sci 2015;60:681-91.

6. Basu P, Ponti A, Anttila A, et al. Status of implementation and organization of cancer screening in The European Union Member States-Summary results from the second European screening report. Int J Cancer 2018;142:44-56.

7. Klabunde C, Blom J, Bulliard JL, et al. Participation rates for organized colorectal cancer screening programmes: an international comparison. J Med Screen 2015;22:119-26.

8. Blom J, Yin L, Lidén A, et al. Toward understanding nonparticipation in sigmoidoscopy screening for colorectal cancer. Int $J$ Cancer 2008;122:1618-23.

9. Fritzell K, Stake Nilsson K, Jervaeus A, et al. The importance of people's values and preferences for colorectal cancer screening participation. Eur J Public Health 2017;27:1079-84.

10. Jovanovic V, Mitrovic Jovanovic A, Zivanovic A, et al. Knowledge about cervical cancer, pap test, and barriers to women's participation in screening in Belgrade, Serbia. Eur J Gynaecol Oncol 2017;38:69-75.

11. de Lange SV, Bakker MF, Monninkhof EM, et al. Reasons for (non) participation in supplemental population-based MRI breast screening for women with extremely dense breasts. Clin Radiol 2018;73:759. e1-759.e9:759.e1-759.e9.

12. Rat C, Hild S, Gaultier A, et al. Anxiety, locus of control and sociodemographic factors associated with adherence to an annual clinical skin monitoring: a cross-sectional survey among 1000 high-risk French patients involved in a pilot-targeted screening programme for melanoma. BMJ Open 2017;7:e016071.

13. Hall N, Birt L, Rees CJ, et al. Concerns, perceived need and competing priorities: a qualitative exploration of decision-making and non-participation in a population-based flexible sigmoidoscopy screening programme to prevent colorectal cancer. BMJ Open 2016;6:e012304.

14. van Dam L, Korfage IJ, Kuipers EJ, et al. What influences the decision to participate in colorectal cancer screening with faecal occult blood testing and sigmoidoscopy? Eur $\mathrm{J}$ Cancer 2013;49:2321-30.

15. Bradley DT, Treanor C, McMullan C, et al. Reasons for nonparticipation in the Northern Ireland Bowel Cancer Screening Programme: a qualitative study. BMJ Open 2015;5:e008266.

16. Vermeer NC, Snijders HS, Holman FA, et al. Colorectal cancer screening: systematic review of screen-related morbidity and mortality. Cancer Treat Rev 2017;54:87-98.

17. Wangmar J, Jervaeus A, Fritzell K, et al. Health literacy levels and views about being invited to a colorectal cancer screening program. Acta Oncol 2018;57:743-9.

18. Spielberger CD. Manual for the State-Trait Anxiety Inventory (Form Y): Self-Evaluation Questionnaire. Palp Alto, California: Consulting Psychologists Press, Inc, 1983.

19. Forsberg C, Björvell H. Swedish population norms for the GHRI, HI and STAl-state. Qual Life Res 1993;2:349-56. 
20. von Vogelsang AC, Forsberg C, Svensson M, et al. Patients experience high levels of anxiety 2 years following aneurysmal subarachnoid Hemorrhage. World Neurosurg 2015;83:1090-7.

21. Mårtensson LI, Wångdahl JM. The Functional Health Literacy scaleThe Swedish Version User manual [Skala för funktionell hälsolitteracitetSvensk version Handledning för hur du ska använda skalan]. Version 3.0 ed: Uppsala universitet, Göteborgs universitet, 2016.

22. Mårtensson LI, Wångdahl JM. The communicative and critical health literacy Scale- Swedish version User manual [Skala för kommunikativ \& kritisk hälsolitteracitet- Svensk version Handledning för hur du ska använda skalan]. Version 3.0 ed: Uppsala universitet, Göteborgs universitet, 2017.

23. Wardle J, Miles A, Atkin W. Gender differences in utilization of colorectal cancer screening. J Med Screen 2005;12:20-7.

24. Ritvo P, Myers RE, Paszat L, et al. Gender differences in attitudes impeding colorectal cancer screening. BMC Public Health 2013;13:500.

25. Egloff B, Schmukle SC. Gender differences in implicit and explicit anxiety measures. Pers Individ Dif 2004;36:1807-15.

26. Osborne JM, Wilson C, Duncan A, et al. Patterns of participation over four rounds of annual fecal immunochemical test-based screening for colorectal cancer: what predicts rescreening? BMC Public Health 2017;18:81.

27. Lecky DM, Hawking MK, McNulty CA, et al. Patients' perspectives on providing a stool sample to their GP: a qualitative study. Br J Gen Pract 2014;64:e684-e693.

28. Aguado Loi CX, Martinez Tyson D, Chavarria EA, et al. 'Simple and easy:' providers' and latinos' perceptions of the fecal immunochemical test (FIT) for colorectal cancer screening. Ethn Health 2018:1-16.
29. Hou SI. Experience of colorectal cancer screening using a homeadministered kit for fecal occult blood tests among a Chinese worksite population in Taiwan. Psychol Rep 2005;96:178-80.

30. Hidalgo JL, Sotos JR, Herráez MJ, et al. Factors associated with cancer worry among people aged 50 or older, Spain, 2012-2014. Prev Chronic Dis 2015;12:E226.

31. James LJ, Wong G, Craig JC, et al. Beliefs and attitudes to bowe cancer screening in patients with ckd: a semistructured interview study. Clin J Am Soc Nephrol 2017;12:568-76.

32. Berkman ND, Sheridan SL, Donahue KE, et al. Health literacy interventions and outcomes: an updated systematic review. Evid Rep Technol Assess 2011(199):1-941.

33. Dolan NC, Ferreira MR, Davis TC, et al. Colorectal cancer screening knowledge, attitudes, and beliefs among veterans: does literacy make a difference? J Clin Oncol 2004;22:2617-22.

34. Rowlands GP, Mehay A, Hampshire S, et al. Characteristics of people with low health literacy on coronary heart disease GP registers in South London: a cross-sectional study. BMJ Open 2013;3:e001503.

35. Chad-Friedman E, Coleman S, Traeger LN, et al. Psychological distress associated with cancer screening: a systematic review. Cancer 2017;123:3882-94.

36. Pallant J. SPSS survival manual: a step by step guide to data analysis using SPSS. Maidenhead: Open University Press/McGrawHill, 2010.

37. Price B. Managing patients' anxiety about planned medical interventions. Nurs Stand 2017;31:53-63.

38. Galaal K, Bryant A, Deane KH, et al. Interventions for reducing anxiety in women undergoing colposcopy. Cochrane Database Syst Rev 2011;12:CD0006013. 